\title{
Temporal variation in ground-dwelling invertebrate biomass in the Goldfields of Western Australia
}

\author{
Scott A. Thompson ${ }^{1,2}$ and Graham G. Thompson ${ }^{2,3}$ \\ 1,2 ATA Environmental, Dilhorn House, 2 Bulwer Street, Perth, \\ Western Australia 6000, Australia (present address) \\ ${ }^{2,3}$ Centre for Ecosystem Management, Edith Cowan University, Joondalup Drive, \\ Joondalup, Western Australia 6027, Australia \\ ${ }^{3}$ Corresponding author. Email: g.thompson@ecu.edu.au,
}

\begin{abstract}
We examined temporal variation in invertebrate biomass based on pit-trapping data from the semi-arid goldfields region of Western Australia (W.A.). Invertebrate dry biomass varied significantly among taxa, seasons and from year-to-year. There was a peak in dry biomass for all taxonomic groups from September to January that was followed by a significant decline for most families by April, and invertebrate biomass was lowest in midwinter. For Araneae, Blattodea, Scorpionida and Chilopoda there was a significant rapid decline by April, whereas for Coleoptera, Orthoptera and Isopoda the rate of decline was slower. Other than during the winter survey, the dry biomass of Formicidae was unchanged. Chilopoda and Blattodea constituted the highest proportion of the biomass captured and the dry mass of individuals from these taxa was generally higher than that for the other invertebrate taxa. There was a positive correlation between invertebrate biomass and the number of reptiles caught but not with the number of mammals caught.
\end{abstract}

\section{INTRODUCTION}

Invertebrates are important in the functioning of nearly all natural environments and a change in their diversity and abundance can potentially affect the whole ecosystem. One potential impact that stems from their importance is as a prey source for reptiles, some small mammals (e.g., dasyurids) and many birds. Invertebrates are also increasingly being used as indicators of rehabilitation success in a variety of situations (Andersen 1994; Bisevac and Majer 1998, 1999a, 1999b; Lobry de Bruyn 1999; Madden and Fox 1997; Majer and Brown 1997; McGeoch 1998). All too often, one-off surveys are undertaken for terrestrial fauna at a particular site, and the data are used to characterise species richness and abundance or to provide benchmarks against which future impacts on the faunal assemblages are assessed. Such surveys pay little attention to temporal variation (Cowan and How 2004; Thompson and Thompson 2005a).

Our objective here was to: a) characterise seasonal patterns in invertebrate biomass; b) compare seasonal patterns in the Goldfields with those that have been described elsewhere in W.A.; and c) relate invertebrate biomass to the activity of insectivorous vertebrates.

\section{METHODS AND SITES}

We sampled the invertebrates on six occasions (Dec 2000, Jan 2001, April 2001, June 2001, Sept 2001 and Dec 2001) in nine undisturbed sites near Ora Banda $\left(30^{\circ} 27^{\prime} \mathrm{S}, 121^{\circ} 4^{\prime} \mathrm{E}\right.$; approximately $50 \mathrm{~km}$ north of Kalgoorlie, W.A.) to establish the annual cycle of variation in biomass.

Ora Banda lies on Archaen granites that underlie lateritic gravel soils. The vegetation was heterogenous, ranging from Eucalypt-CasuarinaMulga woodlands interspersed with Acacia, to sparsely distributed spinifex (Triodia spp.) and shrubs (Acacia spp.) to dense shrubs (Acacia spp., Atriplex spp., Allocasuarina spp.). The nine undisturbed areas were located in different habitats based on major vegetation types identified for the area by Mattiske Consulting (1995).

Other researchers sampling invertebrates have used small pit-traps filled with a preservative (Andersen et al. 2003; Bisevac and Majer 1999a, 1999b; Brennan et al. 1999). However, based on results of a pilot trial in September 2000, larger invertebrates (e.g., beetles, centipedes, spiders) were not easily caught in small diameter ( $40 \mathrm{~mm}$ ) vials filled with a preservative. Therefore, $20 \mathrm{~L}$ pit-trap buckets without a preservative were 
used for surveying the ground-dwelling invertebrates.

Eight pit-trapping lines, each containing three 20 L PVC buckets and three $150 \mathrm{~mm}$ PVC pipes $(600 \mathrm{~mm}$ deep) that were used as pit-traps, were alternated and evenly spaced along $30 \mathrm{~m}$ long flywire drift fences (250 mm high) at each of the nine study sites. Each trapping line was approximately $20 \mathrm{~m}$ apart. Invertebrates were collected daily using forceps from each of the $20 \mathrm{~L}$ pit-trap buckets, for six days for each of the six survey periods. Invertebrates were not collected from the PVC pipe pit-traps. These same pit-traps were used for surveying reptiles and small mammals (see Thompson et al. 2003; Thompson and Thompson $2005 \mathrm{~b})$. We appreciate that captured vertebrates or other invertebrates may have eaten some of the invertebrates caught in these pit-traps, but we believe that the number destroyed would be low compared to the total abundance, as pit-traps were cleared each morning. Small invertebrates, and in particular ants that died and dehydrated in the pittraps, were very difficult to collect at the bottom of the buckets. As a consequence, we would have under-sampled the very small invertebrates; however, this will have had little consequence on our estimate of temporal variation in terrestrial invertebrate biomass given the magnitude of these variations.

All invertebrates collected were initially preserved in $70 \%$ ethanol. The preserved invertebrates were later sorted into the following groups: Formicidae (ants); Coleoptera (beetles); Chilopoda (centipedes); Blattodea (cockroaches); Orthoptera (grasshopper and crickets); Isopoda (slaters); Scorpionida (scorpions); Araneae (spiders) and others. These particular invertebrate groups were chosen because they are easily identified in reptile and mammal stomach contents and were consistent with how other authors report reptile stomach content data (e.g., Pianka 1986).

The invertebrate catch from all 24 PVC buckets at each site on each day were grouped. All invertebrates were removed from alcohol, placed into vials and dried for four days at $35^{\circ} \mathrm{C}$ in a controlled temperature room under fan-forced airflow. Four days was sufficient to remove the moisture and reach a constant mass. The time taken to dry invertebrates was tested after the first survey period in December 2000. There was no change in invertebrate mass between the third and fourth days of drying. The number of individual invertebrates in each group was counted and all samples were weighed to four decimal places using electronic scales.

\section{Data analysis}

The dry biomass of invertebrates was used for all calculations. Variation in invertebrate biomass among the six survey periods was examined using a full factorial ANOVA [Biomass (g/24 pit-trap nights $)=$ site + taxonomic group + survey period + site group + site*survey period + taxonomic group ${ }^{*}$ survey period + site $^{*}$ taxonomic group ${ }^{*}$ survey period] using statistiXL (http:// www.statistiXL.com/; V.1.5). Variance in the ANOVA model came from differences among the six days of data for each site for each survey period.

Correlation coefficients were calculated to demonstrate relationships between the total invertebrate dry biomass for invertebrate group and the number of reptiles and mammals caught during each survey period. In addition, the number of small dasyurids caught was correlated with invertebrate dry biomass, as they are almost exclusively insectivorous. Significance level at $\alpha=$ 0.05 was used for all analyses.

\section{RESULTS}

During six surveys (7776 pit-trap nights) from December 2000 to December 2001, 15069 individual invertebrates were captured with a total dry body mass of 1402.4 g. Chilopoda, Blattodea and Araneae constituted more than two thirds of the invertebrate biomass captured (Table 1). The 'other' group, which accounted for $9.8 \%$ of the total biomass, included gastropods, mantids, earwigs, stickinsects, moths and larvae. Coleoptera had a higher dry mass than Orthoptera, Isopoda and Scorpionida. The average dry mass for individuals was highest for Chilopoda and Blattodea (Table 1). Counting many of the small dehydrated ants proved to be an impossible task and their individual body mass was not able to be accurately assessed, but it was probably the lowest of the groups assessed.

\section{Among seasons variation in invertebrate biomass}

There was a significant difference among factors (e.g., seasons, taxonomic groups and sites), and a

Table 1 Average mass of individuals and proportion of the biomass represented by each group of invertebrates

\begin{tabular}{lcc}
\hline Group & $\begin{array}{c}\text { Mean individual } \\
\text { dry mass }(\mathrm{g})\end{array}$ & $\begin{array}{c}\text { Percentage } \\
\text { of biomass }\end{array}$ \\
\hline Formicidae & & 3.27 \\
Coleoptera & 0.121 & 11.87 \\
Chilopoda & 0.392 & 25.67 \\
Blattodea & 0.323 & 21.42 \\
Orthoptera & 0.076 & 4.42 \\
Isopoda & 0.020 & 1.78 \\
Scorpionida & 0.093 & 2.50 \\
Araneae & 0.090 & 19.30 \\
Other & & 9.77 \\
\hline
\end{tabular}




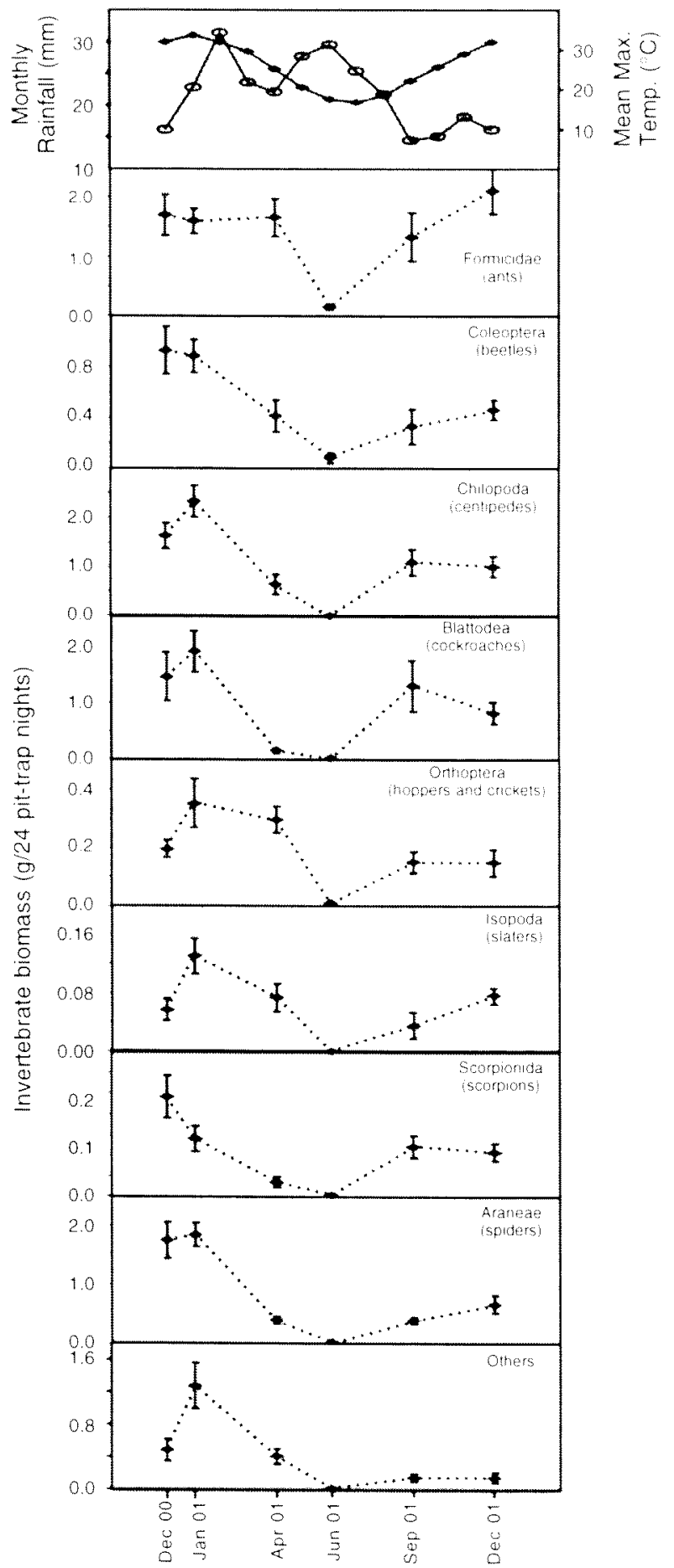

Figure 1 Mean dry biomass for each invertebrate group for each of the six survey periods showing means \pm 1 se. significant interaction among factors for invertebrate biomass (Table 2; Figure 1).

A post-hoc Tukey test after the full factorial ANOVA on all survey periods showed that December 2000 and January 2001 had a higher invertebrate biomass than all other survey periods, including December 2001 (Table 3). June 2001 had the lowest invertebrate biomass. December 2001 biomass was significantly less than December 2000 but the same as for April 2001 and September 2001 (Table 3). A post-hoc Tukey test indicated that Coleoptera and Araneae were the only two families that were significantly different between the two December surveys.

There was no significant difference between the biomass for any taxonomic group for the December 2000 and January 2001 survey periods. With the June catch removed from the dataset, the biomass of Formicidae was not significantly different among the seasons $\left(F_{4,225}=0.80, P=0.53\right)$, whereas for all other taxonomic groups there were significant differences in the dry biomass among seasons (Figure 1). Chilopoda, Blattodea, Scorpionida and Araneae all showed a significant reduction in dry biomass from the January to the April survey period. The decline from January to April was not significant for the other invertebrate groups, but it was significant from January to June. The variation in biomass for Orthoptera and Isopoda, and Chilopoda and Blattodea across the six survey periods were similar (Figure 1). Araneae dry biomass was high for the December 2000 and January 2001 survey periods, then remained low for the subsequent periods.

\section{Abundance of reptiles and mammals relatioe to inertebrate biomass}

There was a positive correlation between the biomass of Coleoptera, Chilopoda, Blattodea, Scorpionida and Araneae and the number of reptiles caught during each survey period, but the total number of mammals and the number of dasyurids caught were not significantly correlated to the dry invertebrate biomass for any of the families (Table 4).

Table 2 ANOVA results for comparison of variation in invertubrate biomass among sites, seasons and taxonomic groups

\begin{tabular}{|c|c|c|c|c|c|}
\hline Source & SS & Df & $M S q$ & $F$-value & $P$ value \\
\hline Site & 41.235 & 8 & 5.154 & 4.403 & $<0.0001$ \\
\hline Season & 258.906 & 5 & 51.781 & 44.234 & $<0.0001$ \\
\hline Group & 400.062 & 7 & 57.152 & 48.821 & $<0.0001$ \\
\hline Site ${ }^{*}$ Season & 90.821 & 40 & 2.271 & 1.940 & $<0.0001$ \\
\hline Site Group & $258 .+12$ & 56 & 4.614 & 3.942 & $<0.0001$ \\
\hline Season* Group & 257.958 & 35 & 7.370 & 6.296 & $<0.0001$ \\
\hline Site*Season*Group & 399.909 & 280 & $1 .+28$ & 1.220 & 0.011 \\
\hline
\end{tabular}


Table 3 Variation in invertebrate mass ( $g / 24$ pit-trap nights) among survey periods. $P$ values are from a post-hoc Tukey test after an ANOVA. Bold $P$ values represent a significant difference.

\begin{tabular}{lcccccc}
\hline Survey period & Mean \pm se & $\begin{array}{c}\text { December } \\
\mathbf{2 0 0 0}\end{array}$ & $\begin{array}{c}\text { January } \\
\mathbf{2 0 0 1}\end{array}$ & $\begin{array}{c}\text { April } \\
\mathbf{2 0 0 1}\end{array}$ & $\begin{array}{c}\text { June } \\
\mathbf{2 0 0 1}\end{array}$ & $\begin{array}{c}\text { September } \\
2001\end{array}$ \\
\hline December 2000 & $0.803 \pm 0.129$ & & & & & \\
January 2001 & $0.968 \pm 0.139$ & 0.22 & & & & \\
April 2001 & $0.273 \pm 0.040$ & $<0.01$ & $<0.01$ & & & \\
June 2001 & $0.020 \pm 0.006$ & $<0.01$ & $<0.01$ & $<0.01$ & & $\sim 1.0$ \\
September 2001 & $0.443 \pm 0.080$ & $<0.01$ & $<0.01$ & 0.19 & $<0.01$ & $<0.01$ \\
December 2001 & $0.436 \pm 0.059$ & $<0.01$ & $<0.01$ & 0.23 & $<3$ \\
\hline
\end{tabular}

Table 4 Correlation between invertebrate family biomass and the number of reptiles and mammals caught during the six survey periods. Bold $P$ values represent a significant correlation.

\begin{tabular}{lcccccccc}
\hline & Formicidae & Coleoptera & Chilopoda & Blattodea & Orthoptera & Isopoda & Scorpionida & Araneae \\
\hline Reptiles & 0.558 & 0.963 & 0.984 & 0.913 & 0.703 & 0.739 & 0.873 & 0.975 \\
Mammals & 0.414 & 0.510 & 0.203 & 0.214 & 0.041 & -0.006 & 0.663 & 0.414 \\
Small dasyurids & 0.474 & -0.152 & -0.274 & -0.188 & -0.305 & -0.165 & 0.111 & -0.275 \\
\hline$P$ values & & & & & & & & \\
Reptiles & 0.250 & 0.002 & $<0.001$ & 0.011 & 0.119 & 0.093 & $\mathbf{0 . 0 2 3}$ & 0.001 \\
Mammals & 0.415 & 0.301 & 0.699 & 0.684 & 0.939 & 0.992 & 0.152 & 0.415 \\
Small dasyurids & 0.342 & 0.774 & 0.599 & 0.721 & 0.557 & 0.755 & 0.834 & 0.599 \\
\hline
\end{tabular}

\section{DISCUSSION}

In the south-west of W.A. there have been a few phenological investigations of invertebrate activity. Majer and Nichols (1998) reported that the number of ants showed appreciable intra- and inter-specific variation over a 14 year period in the forested areas of south-western Australia, with detectable patterns not clearly evident. Postle (1985) reported soil and litter invertebrate numbers around Dwellingup in the south-west of Australia being highest in autumn and progressively declining to a low in December before beginning to increase in February. In contrast, Majer (1985b) and Majer and Koch (1982) reported herbivorous invertebrate numbers were negatively correlated with rainfall at sites at Perth, Dwellingup and Manjimup in the south-west of Australia with lowest numbers in winter, and higher levels of activity in spring, summer and early autumn. Predator insects at the Perth site were most active from late autumn to early spring (Majer and Koch 1982) and low in summer, whereas invertebrate numbers were lowest at Dwellingup in May and June, and at Manjimup in June and July (Koch and Majer 1980). The invertebrate decomposers were most active in winter and spring at the two most northerly sites (Perth and Dwellingup), but at Manjimup, they were most active during summer (Koch and Majer 1980). At Katanning in the wheatbelt to the east of these three sites (e.g., Perth, Dwellingup and Manjimup), ants were most active during the December to March period (Majer 1985a). In the arid Tanami desert, Paltridge and Southgate (2001) reported significant fluctuation in invertebrate biomass between survey periods, with the lowest catch rates being recorded in winter.

Ora Banda is in the semi-arid Goldfields region of W.A. and receives regular winter rain (May to July), and thunderstorms and irregular heavy rain resulting from decaying cyclones and low pressure systems that cross the W.A. coast in the Pilbara during late summer (Figure 1). Summer rain can cause local flooding and leave ephemeral ponds for weeks. Mean monthly maximum summer temperatures are in the low 30 s and drop to the low $20 \mathrm{~s}$ in winter (Figure 1).

The most obvious general feature of invertebrate biomass around Ora Banda was the higher biomass for all families during the summer of 2000/01 and the steady decline into winter and an increase in the following spring. There was no difference in the dry biomass for any taxonomic groups between December 2000 and January 2001. For Coleoptera, Chilopoda, Blattodea, Scorpionida and Araneae, the very obvious peak (Figure 1) in dry biomass during December-January was followed by a significant decline by April and a further drop to June. For Orthoptera and Isopoda, the rate of decline was slower, but the dry biomass for these species was very low in June. For Formicidae, there was no difference among the five survey periods when the June data were excluded. There was no difference in dry biomass for any taxonomic group between September and December 2001, but the overall biomass was higher in December 2000 than in December 2001. These data suggest that the biomass of invertebrates increases rapidly at the end of winter. It then remains the same from September to 
January, and then declines to a low value in mid winter. This is similar to that reported by Majer (1985a) for the semi-arid wheatbelt and Paltridge and Southgate (2001) for the arid Tanami Desert. At other sites in the more mesic south-west of W.A. the pattern seems more variable and perhaps linked to foraging strategy and diet.

Reptiles were most active when the invertebrate biomass was high. This might be expected as a majority of the reptiles around Ora Banda eat invertebrates and, for many, invertebrates are their primary prey. However, many of the small mammals caught (e.g., Cercartetus concinnus, Mus musculus, Pseudomys bolami, $P$. hermannsburgensis) either do not eat invertebrates or they constitute only a small proportion of their diet, and the activity patterns for these species is probably not linked to invertebrate abundance. In contrast, most of the small dasyurids are almost exclusively insectivorous, and it might be expected that their behaviour and activity patterns are linked to invertebrate abundance. However, there was no correlation between the number of small dasyurids caught during each survey period and dry invertebrate biomass. It would therefore be expected that body condition of dasyurids around Ora Banda would be lower in winter when invertebrates were scarce, and they would put on weight in summer because of the increased food supply, and this would be when they are likely to be reproductively active.

Chilopoda and Blattodea constitute the highest proportion of the biomass captured, and the dry mass of individuals was higher than for other invertebrate taxa. Centipedes and cockroaches are generally nocturnal and are therefore probably an important prey source for many of the small mammals in the area. Spiders are also relatively plentiful and vary in dry body mass, providing a range of prey sizes for reptiles, amphibians and small mammals that prey upon them.

Given varying seasonal and year-to-year fluctuations for different invertebrate taxa, the use of the abundance of invertebrates as a bio-indicator of ecosystem restoration should be undertaken with considerable caution. In most circumstances where a faunal assemblage is used as a bio-indicator, there is a presumption that most of the variance in abundance and species richness is directly related to ecosystem development and not environmental or variables unrelated to the restoration success (Thompson and Thompson 2005b). A single terrestrial survey of invertebrates is only able to describe the assemblage for a particular period in time, as relative abundance varies both seasonally and from year-to-year. Therefore, in circumstances where invertebrate monitoring data are used to measure the success of a restoration area compared with an adjacent undisturbed area, the two areas must also be surveyed simultaneously. In most circumstances, our current level of knowledge is such that we cannot separate natural year-to-year variation in invertebrate assemblages or biomass from variations attributable to stochastic events such as fire, grazing, drought or unseasonally heavy or no rainfall.

\section{ACKNOWLEDGEMENTS}

This research was undertaken with ethics approval granted by Edith Cowan University and licences issued by the Department of Conservation and Land Management. This research was financially supported by OMG Cawse Nickel and Barrick Kanowna, for which we are very appreciative.

\section{REFERENCES}

Andersen, A. N. (1994). Ants as Indicators of Restoration Success Following Mining in Northern Australia. In 1994 AusIMM Annual Conference. Australian Mining Looks North - The Challenges and Choices. 5-9 August 1994. Australian Institute of Mining and Metallurgy, Darwin.

Andersen, A. N., Hoffmann, B. D. and Somes, J. (2003). Ants as indicators of minesite restoration: community recovery at one of eight rehabilitation sites in central Queensland. Ecological Management and Restoration 4 Sup: S12-S19.

Bisevac, L. and Majer, J. D. (1998). Invertebrates as success indicators for mine site rehabilitation. In C. J. Asher and L. C. Bell (eds), Proceedings of the Workshop on Indicators of Ecosystem Rehabilitation Success 23-24 October. Australian Centre for Mining Environmental Research, Melbourne.

Bisevac, L. and Majer, J. D. (1999a). Comparative study of ant communities of rehabilitated mineral sand mines and heathland, Western Australia. Restoration Ecology 7: 117-126.

Bisevac, L. and Majer, J. D. (1999b). An evaluation of invertebrates for use as success indicators for minesite rehabilitation. In W. F. Ponder and D. Lunney (eds), The other 99\%: The conservation and biodiversity of invertebrates: 46-49. Transactions of the Royal Zoological Society of New South Wales: Sydney.

Brennan, K. E. C., Majer, J. D. and Reygaert, N. (1999). Determination of an optimal pitfall trap size for sampling spiders in a Western Australian Jarrah forest. Journal of Insect Conservation 3: 297-307.

Cowan, M. A. and How, R. A. (2004). Comparisons of ground vertebrate assemblages in arid Western Australia in different seasons and decades. Records of the Western Australian Museum 22: 91-100.

Koch, L. E. and Majer, J. D. (1980). A phenological investigation of various invertebrates in forest and woodland areas in south-west of Western Australia. Journal of the Royal Society of Western Australia 63: 21-28.

Lobry de Bruyn, L. A. (1999). Ants as bioindicators of soil 
function in rural environments. Agriculture, Ecosystems and Environment 74: 425-441.

Madden, K. E. and Fox, B. J. (1997). Arthropods as indicators of the effects of fluoride pollution on the succession following sand mining. Journal of Applied Ecology 34: 1239-1256.

Majer, J. D. (1985a). Seasonality of ants (Formicidae) in south-western Australia. In P. Greenslade and J. D. Majer (eds), Soil and litter invertebrates of some Australian Mediterranean-type ecosystems, School of Biology, Bulletin number 12, Western Australian Institute of Technology, Perth.

Majer, J. D. (1985b). Seasonality of epigaeic invertebrates at Perth, Dwellingup and Manjimup. In P. Greenslade and J. D. Majer (eds), Soil and litter invertebrates of some Australian Mediterranean-type ecosystems, School of Biology, Bulletin Number 12, Western Australian Institute of Technology, Perth.

Majer, J. D. and Brown, E. (1997). The role of invertebrates in ecological functioning. In C. J. Asher and L. C. Bell (eds), Fauna habitat reconstruction after mining, 10-11 October 1997, Australian Centre for Mining Environmental Research, Adelaide.

Majer, J. D. and Koch, L. E. (1982). Seasonal activity of hexapods in woodlands and forest leaf litter in the south-west of Western Australia. Journal of the Royal Society of Western Australia 65: 37-45.

Majer, J. D. and Nichols, O. G. (1998). Long-term recolonisation patterns of ants in Western Australian rehabilitated bauxite mines with reference to their use as indicators of restoration success. Journal of Applied Ecology 35: 161-182.

Mattiske Consulting Pty Ltd (1995). Flora and vegetation of the Cawse find area, Woodward-Clyde, Perth.
McGeoch, M. A. (1998). The selection, testing and application of terrestrial insects as bioindicators. Biological Reviews of the Cambridge Philosophical Society 73: 183-201.

Paltridge, R. and Southgate, R. (2001). The effect of habitat type and seasonal conditions on fauna in two areas of the Tanami Desert. Wildlife Research 28: 247260.

Pianka, E. R. (1986). Ecology and natural history of desert lizards: Analyses of the ecological niche and community structure, Princeton University Press, Princeton.

Postle, A. C. (1985). Density and seasonality of soil and litter invertebrates at Dwellingup. In P. Greenslade and J. D. Majer (eds), Soil and litter invertebrates of some Australian Mediterranean-type ecosystems, School of Biology, Bulletin Number 12, Western Australian Institute of Technology, Perth.

Thompson, G. G., Thompson, S. A., Withers, P. C. and Pianka, E. R. (2003). Diversity and abundance of pittrapped reptiles of arid and mesic habitats in Australia: Biodiversity for environmental impact assessments. Pacific Conservation Biology 9: 120-35.

Thompson, S. A. and Thompson, G. G. (2005a). Temporal variation in reptile assemblages in the Goldfields of Western Australia. Journal of the Royal Society of Western Australia 88: 25-36.

Thompson, G. G. and Thompson, S. A. (2005b). Mammals or reptiles, as surveyed by pit-traps, as bio-indicators or rehabilitation success for mine sites in the goldfields region of Western Australia? Pacific Conservation Biology 11: 268-286.

Manuscript received 17 August 2005; accepted 24 August 2006 